\title{
Alejandro Korn
}

\author{
(FILOSOFIA ARGENTINA)
}

UERTo Alejandro Korn, en 1936, la Universidad Nacio-
nal de La Plata, de la que Korn habia sido por año profesor, decidió editar, como homenaje de la institución, las obras completas del autor. Salieron éstas a luz en dos volúmenes (Volumen primero: Ensayos filosóficos: Apuntes filosóficos, $X X I X+236$ pp.; Volumen segundo: Filósofos y sistemas: Notas bibliográficas y cartas, 340 pp.), en La Plata, en 1938 y 1939. A la edición, cuidadosamente preparada y bien presentada, acompaña un trabajo introductorio del profesor Francisco Romero en el que se indican, con claridad y precisión, las líneas generales de la personalidad y pensamiento filosófico de Korn. La biografía de éste va incluída al final del volumen segundo, y es la contribución de Luis Aznar. El trabajo del señor Romero y el del señor Aznar, éste retocado y ampliado, fueron posteriormente editados en volumen aparte: Alejandro Korn, Editorial Losada, Buenos Aires, 1940, 138 pp. Este volumen incluye también un trabajo de Angel Vassallo: "Presentación de Alejandro Korn, filósofo" y dos apéndices: "Recuerdo de Alejandro Korn" y "El testamento de un filósofo", por Francisco Romero.

Aunque la personalidad de Korn es ya bastante conoci$d a$, no nos ha parecido fuera de lugar dar aqui una idea de su pensamiento filosófico, según la hemos ido recogiendo de la lectura de los citados volímenes. E1 subtitulo "Filosofía Argentina" que damos a estas notas no indica por de pronto más que una orientación, precisamente la que Korn sugería. 
"La Filosofía -así en singular- no existe. Esta palabra no significa más que amor al saber. Expresa una actitud, un anhelo, un estado de ánimo: el deseo de llevar nuestro conocimiento hasta sus últimos límites. No es, pues, un saber concreto y transmisible sino una actitud espiritual: en ocasiones ésta se puede sugerir y aun encaminar, cuando preexiste una disposición espontánea. Se adquiere así el hábito de dar al pensamiento una dirección determinada, de vincular el caso particular a conceptos generales, de ver en el hecho más común un problema, de empeñar el esfuerzo de la mente en una contienda con lo desconocido, de superar la limitación individual. $\mathrm{Y}$ esta tensión espiritual, este afán de saber, es el mejor provecho de los estudios filosóficos. La mera erudición es un peso muerto, como la carga de la acémila" (Vol. I, 155).

Quien así escribe no es, desde luego se advierte, un filósofo profesional - un profesional de la filosofía. Un filósofo profesional cree, o aparenta creer, en la Filosofía, así, en singular, $y$ hasta con letra mayúscula. Luego, es claro, surge la dificultad: ¿Qué es Filosofía? - pregunta en torno a la que el filósofo profesional luce sus habilidades.

Sin embargo, Alejandro Korn fué profesor de filosofía. Lo fué desde 1906, y por veinticuatro años, hasta 1930, en la Facultad de Filosofía y Letras de Buenos Aires y en la Facultad de Humanidades de La Plata. Pero fué un profesor de vocación, no sólo de oficio; por determinación de su espíritu, no sólo por exigencia del cargo. Un profesor, además, llegado a la filosofía del campo de la medicina. El caso no. es tan raro que no tenga abundantes precedentes. En el mundo del saber y pensar orientales ha sido y es cosa corriente; los nombres más ilustres del pensamiento arábigo-judío son aún hoy los de los médicos-filósofos y filósofos-médicos: Averroes, Avicena, Maimónides... En la misma cultura griega, maceración de frutos occidentales en jugos orientales, medicina y filosofía van tan juntas, que no es raro verlas confundidas. Hipócrates era medio filósofo; Pitágoras era, pa- 
rece, medio médico. En fin, saltando sobre siglos y sobre continentes, en la misma Argentina la presencia del médico en el pensar filosófico y cultural del país mereció ya la atención de José Ingenieros, de quien nos place reproducir aquí las siguientes palabras: "Aprendiendo a meditar sobre las inquietudes del cuerpo se adiestran los médicos para sondar las del espíritu; el misterio de la enfermedad que tortura la entraña lleva a la contemplación del vicio que mina a la sociedad; el problema de la vida sobre la tierra conduce a plantear el de ésta en el universo; la muerte enseña a pensar sobre la falacia de todas las cosas humanas, perecederas como el hombre mismo. El estudio de las ciencias médicas ensancha el horizonte mental de los pensadores que lo emprenden; en todo tiempo hubo médicos que descollaron como humanistas". (1)

Sugestiva es la alianza de estas dos, aparentemente, tan diversas disciplinas consagradas al cuidado del cuerpo y al cuidado del espíritu. Al fin, cuerpo y espíritu van también juntos, y juntos aparecen, actuándose recíprocamente, en la unidad viviente del ser humano. A su manera, es el médico un filósoio, y una especie de medicina es la filosofía. Así lo entendió también el genio de Paracelso -otro médico-filósofo- y con razón, acaso, hizo de la filosofía uno de los puntales de la medicina.

Médico fué Alejandro Korn, y, por añadidura, alienista: director del hospital de alienados de Melchor Romero. Que esta su profesión de médico y de médico alienista hubo de influir en su pensar filosófico, es indudable. Acaso el convencido realista que, a vueltas de todo su,idealismo, se encuentra siempre en Korn, se explique por esta influencia médico-científica. Acaso también el que es uno de los rasgos más acusados de su disposición intelectual: un fundamental escepticismo respecto a la validez del razonamiento lógico, y nada más que lógico, sin la base del hecho real que lo apoye y demuestre. "No hay absurdo que no se haya probado con rigor lógico; la historia de la filosofía lo comprueba... La función lógica, con igual eficacia, demuestra el pro y el contra. Dos alegatos opuestos pueden ser ambos de una lógica rigurosa. También pueden ser falsos uno y otro; el delirio mismo de 
los insanos no carece de lógica... Viejo alienista, no puedo olvidar que hasta el paranoico sistematiza su delirio con impecable lógica" (I, 86, 200; II, 316-7).

$\mathrm{Y}$ ya esto de por sí nos sugiere una de las razones por las que el autor no cree en la existencia de una filosofía, así, como él dice, en singular. Porque, efectivamente, desprovista de base propiamente científica, reducida a depender en gran parte de la razón y la lógica, lo que suele llamarse filosofía, así, en singular; es decir, lo que cada filósofo o cada escritor (al fin, los filósofos son contados) de filosofía llama, singularizando la suya, la filosofía, es sólo, cuando más, una filosofía, una de tantas entre tantísimas. No; la filosofía, así, en singular, mirado el fenómeno en su proyección histórica, no existe; lo que existe es un abigarrado plural de teorías, doctrinas, métodos, sistemas, etc.; no una filosofía sino un laberinto, un caos de filosofías, cada una de ellas condicionada por la particular subjetividad de su autor, a su vez condicionada por la particular subjetividad étnica del grupo a que el autor pertenece.

El espectáculo tiene bastante de deprimente. Abrase un diccionario filosófico, el clásico de Eisler, por ejemplo. Más de doce sólidas páginas dedica la edición $\left(3^{\mathfrak{a}}\right)$ de 1910 a registrar ideas, reflexiones y definiciones acerca de lo que haya de entenderse por filosofía y lo filosófico. Cierto; las diferencias son muchas veces irrelevantes; mera cuestión de palabras; pero son también muchas otras veces fundamentales, ya en lo que respecta a la naturaleza de la disciplina en sí, ora considerada como ciencia de la naturaleza, ora como ciencia del espíritu, ya en lo que se refiere a su contenido, finalidad, etc. Con un poco de buena voluntad podemos, acaso, retener de entre toda esta balumba de concepciones la más fundamental derivada del significado de la palabra: el amor al saber. Pero aun el sentido de este común denominador es equívoco y trastocado aparece a través del proceso histórico, entendido el amor al saber, ora como una aspiración y una tendencia hacia un saber superior y más fundamental que el ordinario del conocimiento científico, ora como la realidad actual y concreta de un saber variado, múltiple, enciclopédico. Concepción esta debida, sin duda, en buena 
parte al menos, a la influencia del genio universal de Aristóteles, y concepción que tantas veces amenazó hacer de la filosofía una a modo de enciclopedia Espasa, o cosa por el estilo.

Las aguas, $\sin$ embargo, corren río abajo y no río arriba. Lo que en otros tiempos fué el árbol frondoso de la filosofía aparece hoy - Korn lo advierte - fraccionado y desmochado en porción de disciplinas y ramas independientes, cada una con su contenido propio. Pero no es fácil para el que una vez ha sido rico resignarse a la pobreza. Por eso, descartada ya, por inadecuada e imposible como base de la concepción filosófica, la realidad concreta de un tal saber enciclopédico, quédale aún a la filosofía la romántica aspiración, si no precisamente a un saber enciclopédico, a un saber unificado $y$ sintético de los primeros y postreros principios; algo que, de ser verdad, vendría a hacer de la filosofía como una ciencia. de la ciencia. En último término quédale la romántica aspiración de dar con un primer principio alfa y omega de todo el saber; un principio único que venga a ser como la clave del gran misterio: el enigma de la Esfinge descifrado. No está mal una tal aspiración; ha servido, sobre todo, para forjar los sistemas de que hoy - hoy que ha pasado la hora de los sistemas- se enorgullece la historia de la filosofía. Filosofía que se definía exactamente por esa aspiración y esa búsqueda. Lo grave es que para llegar a dar con tales principios primeros y postreros, y, sobre todo, con tal principio clave, hay que saltar por encima de la realidad de la experiencia; es decir, hay que salir de lo físico para entrar en lo metafísico; abandonar lo objetivo por lo subjetivo; lo relativo por lo absoluto; el mundo de las cosas y los hechos por el mundo de las especulaciones y construcciones más o menos de razón y más o menos lógicas. Exactamente lo que tantísimas veces ocurrió en la historia de la filosofía y lo que el siglo XIX -el siglo de los sistemas - repitió hasta la saciedad. Poco importa que los filósofos y los sistemas aparezcan en oposición los unos con los otros, ora como idealistas, ora como realistas; la oposición es obligada una vez que se trata de especulaciones y arquitecturas de pura razón (recuérdese la apreciación de Korn respecto a la validez de la función lógi- 
ca). Como quiera que los filósofos y los sistemas se llamen, el resultado es siempre el mismo, y lo mismo significa, para los efectos de su valor científico, el monismo idealista de los unos que el monismo realista y seudo-científico de los otros. Trátase en tales casos de filosofía que es pura y simple metafísica, $\mathrm{y}$, como en el caso de los realistas y positivistas suele ocurrir, mala metafísica.

Ahora bien; la actitud de Korn es en esto decidida: la metafísica es una necesidad imperiosa; hay que hacer metafísica, porque así lo exigen la razón, el corazón y la vida. Hay que hacer metafísica, pero... En primer lugar, la metafísica no es filosofía, o viceversa. $\mathrm{Y}$ en segundo lugar, $\mathrm{y}$ sobre todo: "Se impone una conclusión paradójica: la metafísica es necesaria, la metafísica es imposible" (I, 203). Es un discípulo de Kant quien así se expresa, un "Kantiano relapso". Imposible la metafísica como ciencia, como conocimiento cierto, y reducida, por consiguiente, a un valor subjetivo. En otro lugar de su obra, recordando el consejo de Croce de que debe leerse a Hegel "come si legge un poeta", Korn lamenta tan sólo que el filósofo italiano no generalizase el consejo; "debió - dice- haberlo extendido a todos los sistemas metafísicos habidos y por haber" (II, 104). Tal es el valor concedido por Korn a la metafísica: el de una expresión poética. $Y$ lo que de la metafísica se dice vale igualmente para la fenomenología, "último producto de la filosofía de la cátedra" ( $(1,82)$, por no ser esta fenomenología en el fondo otra cosa sino metafísica.

Por vía de resumen. La filosofía no es la serie de teorías, doctrinas y sistemas contradictorios que forman el contenido de la historia de la filosofía. La filosofía no es la realidad concreta de un saber enciclopédico. La filosofía no es la metafísica ni es la fenomenología. ¿Qué es, pues, la filosofía?

Podemos desde luego repetir que es -sigue siendo- el amor al saber. Ahora, descartado ya aquel otro sentido del amor al saber como actualización del saber y saber concreto, conjunto de conocimientos más o menos enciclopédico, lo que nos queda es el amor al saber como aspiración, o digamos, repitiendo las palabras de Korn, como "una actitud..., una 
actitud espiritual". Por propia cuenta preferiríamos nosotros sustituir el verbo "saber" por el verbo comprender, que expresa mejor, parécenos, la índole por esencia problemática del inquirir filosófico. Se saben cosas y hechos; se comprenden, o por lo menos se ven y se plantean, problemas.

Otro significado, además del original del amor al saber, tiene aún para Korn la filosofía. Tiene ésta también un cierto contenido. Este contenido se define por razón del dualismo sujeto-objeto, dualismo en torno al cual gira el discurrir filosófico del autor argentino.

He ahí, de un lado, el mundo de lo real: cosas, hechos, fenómenos - mundo exterior y extraño a la voluntad del hombre, regido por la ley de la necesidad. Mundo que no es dado y que no cabe, por consiguiente, ni afirmar ni negar; todo lo que puede hacerse es comprobarlo por la experiencia, reducirlo a objeto de estudio y de conocimiento. Tal es, en efecto, la misión de la ciencia y tal es el objeto, bien concretamente definido, de la ciencia. El término resulta en extremo confuso, aplicado como constantemente aparece a las más diversas disciplinas y a las más vacuas especulaciones. Para Korn, sin embargo, atrincherado en el dicho dualismo, el significado es preciso. Dominio de la ciencia es, dice, el orden objetivo. El orden objetivo, es decir, lo espacial, lo extensivo, lo mesurable; algo, pues, sometido a medida, sujeto a matemática. "Merced a las matemáticas, el conocimiento se eleva a ciencia. Aquello que no puede matematizarse nunca será ciencia. Si todo fuera susceptible de ser matematizado, la realidad sería un enorme mecanismo en el cual la más diminuta célula vibraría sometida al sortilegio pitagórico del número. $\mathrm{Y}$ eso es efectivamente el ideal de la ciencia, realizable si todo fuera objeto y se suprimiera el molesto obstáculo subjetivo" (I, 88). La definición se impone: "La ciencia es la interpretación cuantitativa de la realidad" (I, 88).

No quiere decir el autor, es claro, que la realidad se agote en esa determinación cuantitativa. Expresamente advierte 
que la ciencia "no capta la totalidad, sino un aspecto de lo real" (I, 88). Fuera de ella queda por de pronto todo lo que no es mensurable, cantidad; por consiguiente, todo lo que es calidad. $\mathrm{Y}$ aun de lo restante, más que una transcripción exacta, lo que la ciencia nos da es, en final de cuentas, una abstracción matemática. Ahora, que quien pretenda ir más allá de ese aspecto cuantitativo de las cosas, no será ya ciencia lo que hará; hará metafísica, o filosofía, o cualquiera otra cosa.

Tal es, pues, el dominio de la ciencia: el mundo espacial, la naturaleza, el cosmos, en cuanto mensurable. $Y$ apenas hay que decir que así definida la ciencia, como ciencia exacta, matemática, quedan automáticamente descalificadas, por extrañas a semejante concepción físico-matemática, todas las infinitas disciplinas designadas con los pintorescos nombres de ciencias del espíritu (incluyendo buena parte de la así titulada Psicología experimental), ciencias sociales (empezando por la Sociología), ciencias culturales, etc. Trátase en tales cases, según Korn lo advierte, de seudo-ciencias, o trátase de lo que el autor llama "teorías". Y si lo que se pretende es superar el conocimiento basado en la experiencia para llegar hasta el ser último de las cosas, trátase entonces de meros "alegatos metafísicos" (I, 85). La misma biología será ciencia sólo cuando disponga de hechos mensurables. $Y$ en cuanto a la actitud subjetiva, el proceso psíquico y el proceso histórico, son de otro orden: "Aunque hechos empíricos, sólo se desenvuelven en el tiempo; por carecer de espacialidad no son mensurables. Su conocimiento no puede reducirse a fórmulas aritméticas" (I, 208-9). No son tampoco, por lo tanto, eiencia.

Por limitada que pueda parecer esta concepción, Korn no entiende con ello rebajar en modo alguno el valor de la ciencia. Bien que reconociendo el hecho de que toda ciencia (y toda verdad científica) vale en definitiva sólo de una manera relativa, ya porque en ningún caso coincide con la realidad total de las cosas, ya por razón del cambio constante a que toda realidad está sometida, hipótesis e inferencias meta-empíricas de que la ciencia se sirve, ya, en fin, por el valor sólo aproximativo y de probabilidad, no de absoluta exactitud, de 
las conclusiones y leyes a que en cada caso llega, con todo, y a pesar de todo, en la ciencia (ciencias exactas) reconoce Korn "el mejor caudal de la humanidad..., el capital más saneado de la cultura, la creación más alta de la inteligencia humana" (I, 90, 212). Cualesquiera que puedan ser los reparos teóricos que sobre ella se formulen, su justificación está en su misma eficacia técnica. Ni la ciencia, como tanto se ha dicho y repetido, ha hecho bancarrota; lo que hizo bancarrota fué la manía cientificista del positivismo al pretender hacer ciencia de todo problema y de toda lucubración.

Ahora, así abandonado a la ciencia el orden objetivo, frente a él preséntase el orden subjetivo; frente al objeto, el sujeto, el hombre-puente tendido entre los instintos del simio y la visión del superhombre. Confundido al aparecer sobre la superficie del planeta con el resto de los animales, sólo de ellos separado por diferencias anatómicas, y como los demás animales sometido al imperio de las fuerzas físicas que lo rodean, poco a poco, a medida que se va esclareciendo y afirmando su conciencia, empieza a desligarse de esa su primera dependencia del medio. Lejos de adaptarse pasivamente, se rebela afirmando la libre determinación de su voluntad, cuyo imperio logra al fin imponer a la naturaleza hasta hacerla servir a sus fines. Un nuevo orden aparece así frente al orden de la naturaleza: el orden de la cultura, creación de la voluntad humana. Orden aquél de hechos objetivos, regido por leyes necesarias, gobernado por el principio mecánico de la causalidad; orden éste de determinaciones subjetivas, regido por la voluntad del hombre en vista de finalidades a realizar apreciadas como valores.

Frente al orden de los hechos, el hombre no permanece pasivo. No puede, es claro, suprimir los hechos, pero puede reaccionar y efectivamente reacciona frente a ellos, apreciándolos en cada caso con su criterio personal como útiles o nocivos, buenos o malos, etc., y, en fin, por determinación de su voluntad libre, afirmándolos o negándolos, es decir, valorándolos. "Valoración" - define Korn-es "la reacción de la voluntad humana ante un hecho". Resuélvese esa valoración frente al hecho en un "lo quiero o no lo quiero". "Valor" es "el objeto de una valoración afirmativa" (I, 102). Lo que 
se dice la cultura es "la expresión de los valores que (la especie) ha afirmado" $(I, 83)$.

Específicamente, es éste el orden asignado por Korn a la filosofía como su dominio propio: el orden subjetivo, el orden de la voluntad humana, que en Korn viene a coincidir con el orden de los valores. Filosofía que es, pues, axiología: teoría de los valores, y así, en efeecto, es como la llama el autor. "La filosofía..., teoría de la actividad subjetiva..., no es nada más que axiología" (I, 228). La misma gnoseología no es tampoco más que axiología: "teoría estimativa del valor del conocimiento" (I, 65). "Disolvamos, pues - acaba por decirnos el autor - el conglomerado de la vieja filosofía y despidámonos de ella. Conservemos su nombre auspicioso para designar una actitud espiritual, pero repartamos su acervo común, entre la Ciencia, la Axiología y la Metafísica. Gobierne aquélla el orden de los hechos objetivos y halle la fórmula matemática que los rige; penetre ésta en el secreto de la voluntad humana e intente, la última, referir la realidad a conceptos que trascienden toda experiencia posible". $(I, 65)$.

Por esta su concepción de la filosofía como axiología, enlázase el pensamiento de Korn con la que es acaso la tendencia dominante en el pensar filosófico contemporáneo, en Alemania paríicularmente, donde, en variedad de direcciones, el problema todo de los valores viene desde hace años ocupando el centro de la atención y la especulación filosóficas. (2) Y no sólo del pensar filosófico, ya que el mismo problema es planteado en porción de otras disciplinas, por teólogos y psicólogos, por sociólogos y economistas, incluso por fisiólogos y biólogos. (3) Es natural, si es verdad, como así es, que el problema de los valores es en último término el problema de la cultura. Más aún; es el problema del sentido de la vida misma del hombre, sentido que depende, en conclusión, de los valores..., los valores que a esa vida dan, o pueden dar, sentido. Problema por naturaleza múltiple y complejo y en el que todo es, efectivamente, problemático, tan problemático como problemáticas son la cultura y la vida humanas.

Caballo de batalla es en este caso, ante todo, decidir qué es lo que haya de entenderse por valores; es decir, qué son los valores, cuál es su verdadera naturaleza, problema de 
solución acaso imposible dado lo dudoso e inseguro de los conceptos básicos (del ser, sujeto y objeto, lo subjetivo y objetivo, etc.) que el problema plantea y sobre los que se apoya. Igual, la cuestión toda de la jerarquía o rango de los valores. Sin entrar en el asunto, digamos tan sólo, concretándonos al caso de Korn, que su concepción de los valores es tan definida y definitiva como su concepción de la ciencia, y ambas concepciones se corresponden y complementan.

Frente al hecho objetivo, asunto de la ciencia, son los valores, asunto de la filosofía (axiología), algo enteramente subjetivo; algo, por consiguiente, por naturaleza relativo. Con lo cual dicho está también que la axiología no es, no puede ser, una ciencia, como no lo es ni puede serlo ninguna de las disciplinas axiológicas: ética, estética, derecho, etc. Lo que se dice valores universales y eternos, valores objetivos, necesarios para todos, valores absolutos, no existen. No lo son los valores lógicos, ni los éticos, ni los estéticos, ni ninguno. Son todos los valores, por el contrario, productos históricos, sujetos a constante transmutación. Cada generación, cada pueblo, cada individuo, se forja los suyos, y hoy unos y mañana otros. No cabe separar, sin salirse de los límites de la realidad empírica, el valor de la valoración; no existen valores independientes de la valoración; y la valoración representa, en última instancia, "la decisión de la personalidad autónoma" (I, 132). No es discutible la realidad empírica de las cosas; se la observa y se la comprueba. Sobre su valoración, en cambio, se discute eternamente sin jamás llegar a ponerse de acuerdo. - Ello explica también el por qué de la existencia de tantas filosofías particulares frente a la exigencia de una sola verdad filosófica. Es que, dice Korn, "cada filosofía distinta es la expresión de una valoración distinta", sujeta, por consiguiente, "a la suerte fluctuante de las valoraciones. Toda filosofía sistematiza en un alegato la voluntad que la inspira" ( $I$, 145).

Lo que con la naturaleza de los valores ocurre, ocurre igualmente con su ordenación jerárquica. Tampoco para esto existe norma o patrón objetivo alguno. A prácticamente todos y cada uno de los valores se les ha asignado por alguien el puesto primero, el lugar supremo, y el mismo Korn dedica 
varias páginas a argüir el pro y el contra de la cuestión respecto a cada una de las nueve categorías de valores que distingue, mostrando así lo subjetivo y relativo de tales asignaciones de la primacía a un cierto valor o a los valores de un cierto orden. Sin duda porque la asignación misma es, como lo es ya la cuestión toda de la subordinación jerárquica de los valores, una valoración, algo, pues, otra vez subjetivo y relativo, y por motivos más que lógicos, cordiales. "En realidad - concluye Korn- no hay una jerarquía objetiva, aunque nos queda el derecho de decretarla por nuestra cuenta" (I, 230).

De un tal relativismo como éste de Korn al más completo nihilismo en todo lo que a los valores se refiere, parece no haber más que un paso. En la práctica, sin embargo, las cosas se pasan de otra manera. Cierto, las valoraciones siguen siendo en cada caso actos individuales; pero el individuo no existe aislado, y hábitos, intereses y aspiraciones de la vida en común acaban por producir también valoraciones y valores comunes, valores colectivos, por todos o la mayor parte de los miembros del grupo o de la comunidad queridos y aceptados. Igual en lo que a la jerarquía de los valores respecta. Nl momento histórico, las circunstancias, deciden en cada caso del orden de primacía entre los diferentes valores. En resumen, trátase en todo esto de una cuestión de índole más bien pedagógica, que ha de resolverse según las exigencias del momento.

Aun con estas aclaraciones y limitaciones, no salva la teoría de los valores de Korn el escollo de la contradicción lógica con que acaba al fin por chocar toda teoría relativista ai darse a sí misma como la verdad absoluta. Admitido que todo sea relativo, relativos habrán de ser también la verdad y valor del mismo relativismo. En resumen, más que excluir la verdad y el valor absolutos, lo que el relativismo hace es postularlos y exigirlos.

Por lo demás, adviértese en la discusión toda de los valores de Korn que el autor identifica los conceptos del ser y to objetivo con el ser y lo objetivo empíricos, como dados en la realidad tempoespacial. Lo demás lo rechaza como pura metafísica. Ello es cuando menos discutible, pero ilustra en 
todo caso el sentido último realista, y la clase de realismo, del pensar filosófico del autor.

\section{III}

En la historia de la cultura argentina ocupa Korn un lugar especial, representativo. Encarna, en efecto, el espíritu de la reacción frente al hasta entonces triunfante espíritu del positivismo. Semejante reacción no es en sí misma, por supuesto, nada específicamente argentino; es un fenómeno general en la historia de la cultura occidental. Orientada ésta por las vías del romanticismo y del idealismo durante la primera mitad del siglo XIX (aunque las obras de Comte aparecen ya en esta primera mitad), oriéntase ahora, durante los años de la segunda mitad de ese siglo, por las vías del positivismo. En parte, como reacción contra esos mismos romanticismo e idealismo, evidentemente ya exprimidos y agotados, sobre todo, como natural consecuencia de las influencias científicas y técnicas, económicas, incluso políticas y sociales que hacía tiempo venían empujando la realidad de la vida moderna. No importan mayormente las etiquetas, distintas en los distintos campos de la actividad humana: positivismo, materialismo, realismo, naturalismo, etc. Un cierto confusionismo entre literatura y ciencia, también entre ciencia y literatura, no es raro en el positivismo, y sabido es que Zola elaboró su "Roman expérimental" - la teoria, se entiende-con enseñanzas y deducciones de Taine y Claudio Bernard. Cualesquiera que puedan ser las etiquetas, el producto es poco más o menos el mismo. Trátase, como más evidente, de volver la espalda a todo lo que sea trascendente y metafísico, sobrenatural y celestial, para concentrar la mirada en la realidad de la tierra. "Dios ha muerto... Permaneced fieles a la tierra y no creáis a los que os hablan de esperanzas sobrenaturales... El corazón de la tierra es de oro" - sermoneaba Zarathustra. $Y$ hasia el manso y suave Renan erigia un tabernáculo en su corazón, tan inflamado de nostalgia de Dios, a la ciencia y a la realidad de la tierra representada por la ciencia. 
Fué la ciencia, o más bien lo científico, en efecto, el nuevo ídolo que ahora vino a sustituir a la vieja metafísica y a la viejísima teología. La ciencia era, o debía ser, en exacta adecuación de términos, la realidad, y la realidad eran los hechos - hechos empíricos, materiales, como los que la realidad física nos ofrece. Observar, describir, clasificar y relacionar estos hechos, buscando en cada caso la ley de su coordinación y dependencia, era la misión de la ciencia (a veces también de la literatura). Con un sentido materialista de la. vida por fundamento, acaba así el positivismo por reducir el universo a un enorme mecanismo de causas y efectos. De ese vasto mecanismo no es tampoco el hombre más que una de las tantas piezas, movido y determinado por un proceso de fuerzas físico-químicas.

Como el idealismo había querido hacer del mundo físico una prolongación de la conciencia individual, quiso el positivismo hacer de la conciencia individual unà prolongación del mundo físico. Allí y aquí lo que se busca es acabar con el dualismo sujeto-objeto, por la absorción del objeto en el sujeto, en un caso; por la absorción del sujeto en el objeto, en el otro caso. En ambos, coincidiendo en esto fundamentalmente idealismo y positivismo, la aspiración es llegar a un absoluto monismo; dar con un primero, único y absoluto principio que lo incluya y explique todo, llámese el tal principio como se quiera y como quiera que se lo conciba, ya como algo orgánico, ya como algo mecánico.

Sería un error creer que el positivismo acabó de una vez allá, digamos, por los años finales del siglo pasado. Vivo sigue aún el espíritu que lo informó en la conciencia de millones de gentes, entre las que se cuentan muchas del mundo académico y profesional. No es menos cierto, sin embargo, que la hora del triunfo del positivismo ha pasado. Si la aparición del popular Enigma del Universo (descifrado, por más señas), de Haeckel, en 1899 (i feliz año y feliz siglo nuevos!), marca de una parte la culminación del movimiento positivista, marca igualmente, de otra parte, el comienzo (un tanto avanzado ya) de su decadencia. La reacción es desde entonces franca y cada día más acentuada. Y esto no sólo en la filosofía sino también en la misma ciencia, en la que una inter- 
pretación cada vez menos mecánica y más orgánica, menos inerte y más activa, menos absoluta y más relativa, tiende a prevalecer. (4)

Es, pues, decimos, como una manifestación más de esta general reacción contra el positivismo que se nos presenta el caso de Korn. Pero si la reacción misma es un fenómeno general, en ella se afirma, por otra parte, la nota más personal de la filosofía del autor argentino: el sentimiento de la dignidad humana. No es sólo, en efecto, por razones de un mero argüir filosófico por lo que Korn rechaza el positivismo. Tales razones existen, sin duda; mucho tiempo hace que son conocidas y Korn las hace valer una vez más, al recordarnos, por ejemplo, que es sólo como un fenómeno mental como se nos presenta y conocemos este universo visible y tangible, e igualmente los elementos del tiempo, el espacio y la relación de causa a efecto en que ese universo se nos aparece. Nada, en conclusión, existe fuera de la conciencia, y de las fronteraś de la conciencia no hay posibilidad de salir. Bien entendido, sin que nada de esto signifique (en la intención por lo menos) identificación última alguna entre el ser y el pensar. Idealista por lo que a su orientación filosófica se refiere, limítase Korn a registrar el modo en que la realidad nos es conocida, sin de ello concluir por eso que la tal realidad sea en sí misma únicamente in fenómeno mental. A vuelta de cuentas, es el de Korn, diremos, un idealismo respetuoso, desde luego para con la realidad última de las cosas, cualquiera que ella pueda ser, y más respetuoso aún para con los métodos y resultados de la ciencia y la técnica en el conocimiento y manejo de esa realidad.

Pero importante como lo es esta razón, no es sin embargo la única, ni acaso la principal, por la que Korn mueve guerra contra el positivismo. Más importante es aún el motivo ético, motivo cuya validez resulta del hecho mismo de que, magnífico como lo ha sido el progreso científico y técnico llevado a cabo, el resultado de ese progreso aparece, en final de cuentas, como un verdadero "desastre" (I, 9). 'Vicios y crímenes siguen, poco más o menos, lo mismo; las más atrevidas y atrayentes invenciones acaban por convertirse en armas para el asesinato, etc. Es dudoso, cuando menos, que la 
humanidad haya mejorado con todo ese progreso. Sin perderse en fáciles moralizaciones ni en empalagosos sentimentalismos, sólo como plena y fría realidad de hecho, Korn advierte, como por fuerza ha de advertirlo todo espíritu medianamente delicado, la viva y grotesca paradoja de una civilización en la que, como en la nuestra ocurre, un enorme progreso cultural, intelectual, científico y técnico, coincide con una no menos enorme degradación moral. La paradoja de la cultura aliada con la barbarie.

Frente a una tal paradoja, la reacción de Korn es más práctica que especuiativa. No discute, por ejemplo, el problema que situación tal plantea de la relación entre lo cultural, o dígase lo intelectual, y lo vital; entre la razón y la vida, ni saca tampoco, por consiguiente, conclusión alguna respecto al significado puramente accidental o necesario de semejante paradoja. (5) Creyente al fin en la obra de la razón, en la cultura y en la ciencia, limítase a registrar la insuficiencia de ésta, afirmando la necesidad de subordinarla a un principio superior, "a un principio ético" (I,9). No es ya, pues, como tanto se ha dicho y repetido por la beatería cultural y científica, la cultura por la cultura, ni la ciencia por la cirncia, ni el saber por el saber; es, desde un punto de vista más pragmático, la cultura, la ciencia y el saber por algo y pard algo. ": Se hizo el hombre para la ciencia o se hizo la ciencia para el hombre?" - no se cansaba de preguntar don Miguel de Unamuno. Sin las angustias místicas de éste, pero con idéntico sentido de orientación humana, la pregunta no puede tener para Korn más que una respuesta: la ciencia (y la cultura toda) es un medio para un fin - fin que es el ser humano, el hombre, y al hombre ha de ser, por consiguiente, subordinada.

El hombre, sin embargo, fué la víctima sacrificada por el positivismo de antaño, como suele serlo por el cientificismo de hogaño. Dicho queda: del vasto mecanismo a que redujo el universo, hizo el positivismo del hombre una de las tantas piezas, un objeto, una materialidad más, y, como tal, regida por la misma ley de hierro de una rigurosa causalidad. Libertad, espiritualidad, subjetividad, son en esta concepción positivista, no ya sólo ni principalmente científica, sino filo- 
sófica, términos vanos y vacuos. Lo subjetivo es aquí sacrificado sin remedio a lo objetivo, o a lo que por tal es tenido; la persona a la cosa, el espíritu a la materia, la libertad a la necesidad. La psicología redúcese a mecánica social y proceso físico-químico, a sociología y a fisiología.

No hay lugar en semejante concepción científica para la libertad; tampoco, consiguientemente, para la ética, pues no hay ética sin responsabilidad ni hay responsabilidad sin libertad. "Espectáculo raro - comenta Korn- ver a estas gerieraciones resueltas a conquistar en lucha sin tregua todas las libertades - política, económica, intelectual-negar asimismo la libertad intrínseca del hombre. Al propio tiempo, persiguen un ideal humano y abrigan la esperanza de realizarlo sin un principio normativo de la conducta" $(I, 8)$. Lo que se llama la ética resuélvese en un más o menos crudo utilitarismo, unas veces; resuélvese otras veces en un vago sentimentalismo humanitario.

Contra una tal concepción mecanicista dirige Korn todas sus críticas; frente a ella se define el sentido de su filosofía, como, en general, el de la nueva filosofía. "La nueva filosofía ha de libertarnos de la pesadilla del automatismo mecánico $y$ ha de devolvernos la dignidad de nuestra personalidad consciente, libre y dueña de su destino. No somos la gota de agua obediente a la ley del declive, sino la energía, la voluntad soberana que rige al todo. Si queremos un mundo mejor, lo crearemos... No esclavos, señores somos de la naturaleza" (I, 9-10).

Es también, en lo esencial, el significado de la nueva filosofía de los valores, filosofía de raigambre ética, cuando no religiosa (Max Scheler), más dirigida hacia el hombre que hacia las cosas, y en la que el valor tiende a imperar sobre el ser, lo subjetivo sobre lo objetivo, el hombre sobre el mundo, y hasta el individuo sobre la masa.

Así vistas, adquieren también su significado pleno la filosofía de los valores de Korn y la concepción que de estos valores tiene el autor, todo ello como un problema ético, o dígase, de humanidad. De lo que ante todo se trata es de salvar y afirmar lo subjetivo, el principio de libertad, y con 
el principio de la libertad, el principio de la humana dignidad. Frente a la tesis de las cosas como medida del hombre, es el hombre quien vuelve a ser medida de las cosas. No admite Korn, decíamos hace un momento, la existencia de norma o patrón objetivo alguno para la organización jerárquica de los valores. Pero sí admite, por otra parte, que, sin perjuicio đe una autonomía relativa, existe entre ellos una "vinculación estrecha", una "unidad intrínseca" (I, 130), que hace posible su agrupación sintética. Resulta una tal agrupación del hecho mismo de que, nacidas todas las valoraciones como determinaciones de la voluntad autónoma en su trato con el mundo y con la vida, dirígense todas ellas también a un mismo fin, precisamente, a mantener esa autonomía de la voluntad humana - el principio de la libertad, principio que aparece así a la vez como el origen y el término de todas las valoraciones. "Todas las valoraciones - concluye Korn-emergen de una sola fuente y tienden al mismo fin. Afirman la autonomía de la Personalidad, persiguen su emancipación de toda servidumbre, es decir, su liberación como finalidad última y común. La libertad relativa en cada caso, la libertad absoluta como meta ideal" (I, 144). De un tal impulso ha nacido la obra de la cultura, y por una tal actitud, no ya de pasiva sumisión, sino de abierta rebeldía frente a la ley de la necesidad que impera en el orden objetivo, distínguese el hombre del animal.

Habiendo empezado por reducir la filosofía a axiología, acaba Korn, ahora lo vemos, por reducir todos los valores al común denominador de la afirmación de la libertad humana, de la autonomía de la personalidad. Así reacciona el autor contra el mecanicismo del positivismo y, en general, de todo realismo, con una dramática exaltación del principio de la libertad.

Por libertad entiende Korn "la ausencia de toda coerción" (I, 143). Una tal libertad no es por de pronto un hecho, o más exactamente, una actualidad; es una finalidad, un ideal en proceso de realización. Es un devenir. Como actualidad existe sólo la libertad de querer, no de hacer. "El sujeto es autónomo, pero no soberano" (I, 30). Frente a sí tiene el orden objetivo de la naturaleza regido por la ley física de la 
necesidad. El dualismo sujeto-objeto resuélvese en la antinomia libertad-necesidad. En su relación con ese orden objetivo trata el hombre de imponer su voluntad, dominándolo, conquistándose así la libertad económica, tarea en la que le sirven de instrumentos la ciencia y la técnica. No es ésta la forma superior de la libertad, mas es indispensable. Pero además de ese orden de la naturaleza, el hombre tiene frente a sí... otra manera de naturaleza: su propia condición animal y humana: instintos, hábitos, pasiones, etc. Como por el dominio de las cosas consigue el hombre llevar a realización la libertad económica, consigue por el dominio de sí mismo dar actualidad a la libertad ética, que no significa precisamente la repudiación de todo principio y de toda norma. Significa todo lo contrario: la referencia de la voluntad a una disciplina, a una norma superior aceptada como principio de conducta que la voluntad se impone a sí misma libremente. La libertad ética es, sin duda, la forma superior de la libertad y, como la libertad económica, se conquista y agranda en la tarea de cada día.

Cuál haya de ser esa disciplina o norma superior, Korn no lo dice, ni formula imperativo alguno más definido que el vago del cumplimiento del deber, subordinación del egoísmo individual al principio de solidaridad humana, etc. No sería tampoco acaso fácil, desde el punto de vista del autor, formular un tal imperativo, dado lo subjetivo y relativo de todas las valoraciones y de todos los valores. Sin embargo, vinculados entre sí como presenta estos valores por la nota a todos ellos común de servir a una misma y única finalidad: la afirmación de la autonomía de la personalidad, su libertad, el sentido de un tal imperativo, como quiera que se lo formule, habrá de consistir exactamente en esa misma afirmación en cada caso del principio de la libertad, afirmación que vendría a asumir así, diríase, el significado de un valor supremo, absoluto.

\section{$\star$}

En el principio fué la acción. El impulso que mueve al hombre a sostenerse en la lucha diaria por la conquista de la 
libertad, impulso a que debe su origen toda la obra de la cultura, lo llama Korn la "libertad creadora". Prácticamente es esta libertad creadora "acción creadora", o dígase, sencillamente, "acción", y Korn, el filósofo de la personalidad y la libertad, resulta ser también el filósofo de la acción. $Y$ esto porque la vida misma es acción y es por la acción, en definitiva, como se afirma la personalidad y se actualiza la libertad. En cierto modo, son esta libertad y esta acción creadoras en Korn un escape metafísico: un sustituto con que llenar el hueco de la aspiración y la necesidad metafísicas, una vez que la metafísica como conocimiento es imposible y al autor no le es dado colmar el vacío de ese hueco ni con la emoción del artista ni con la fe del creyente, ordinarios sustitutos de la metafísica. "El examen teórico de nuestro conocimiento de la realidad nos deja perplejos; por ninguna vía tocamos la certidumbre. Los hechos empíricos, los conceptos puros, los mitos poéticos, se esfuman ante el análisis. La razón última de las cosas es inasible. La fe es una convicción subjetiva; la lógica termina en antinomias; las valoraciones son contradictorias. Ni el secreto del cosmos ni el secreto del alma se nos entregan. En lugar de soluciones se nos ofrecen problemas; la duda es nuestro patrimonio intelectual. La acción corta este nudo gordiano. Lo corta tras reflexiones meditadas o por impulsos violentos, pero lo corta porque es cuestión de vida o muerte... En el proceso mental de la conciencia, única realidad que conocemos, coexisten la necesidad y la libertad; expresión de un dualismo gnoseológico insoluble. En la supuesta unidad del más allá, estos conceptos carecen de sentido. Su síntesis se realiza en la acción" (I, 232; II, 319).

Va sin decir que por acción no entiende Korn sólo la que se desenvuelve en el plano más inferior de la lucha económica, la vida utilitaria y técnica; es acción que responde también a anhelos de bondad, de justicia y de belleza, como de todos los más elevados ideales.

Heredero de la vieja tradición cultural europea, hijo de un ex oficial del ejército prusiano, pero nacido en la Argentina, refleja el espíritu de Korn ese doble haz de influencias de dos continentes y de dos actitudes vitales: la vieja de Eu- 
ropa, de un sentido más bien pesimista, y la nueva de América, de la Argentina más concretamente, de un sentido predominantemente optimista. Es, de un lado, la mirada vuelta sobre el pasado (tan estéril en tantos sentidos; tan sobrecargado de intelectualismo paralítico) ; y es, de otro lado, la mirada dirigida sobre el futuro (con una materia maleable y rica en posibilidades sobre la que actúe la voluntad). Sin cuda, la visión que de la realidad tiene Korn es pesimista, con ese pesimismo que es el resultado del choque entre un vivo anhelo de bondad, de justicia y de belleza, más un igual vivo anhelo de acallar la inquietud de la conciencia en la calma de una solución final, de una parte, y el espectáculo de una vida donde el mal, la injusticia y la monstruosidad están a la orden del día, y en la que todo es problemático, contradictorio y pasajero, de otra parte. Visión de espíritu realista, visión de espíritu metafísico. Así, contradiciendo la tesis más comúnmente sustentada de la objetividad de los valores, Korn no vacila, dominado por esa visión pesimista, en afirmar que lo verdaderamente real y objetivo es lo otro. No el Bienestar, sino el malestar; no la Dicha, sino el dolor; no el Amor, sino la hostilidad, etc. Lo que se dice los valores aparecen así com. mo "fines ideales de la voluntad", que en sí mismos no son sino "negaciones de fenómenos muy reales... Los conceptos que negamos son precisamente los positivos" (I, 139). A pesar de lo cual, una indomable voluntad de afirmación de la vida, de la personalidad y de la libertad, acaba por orientar el espiritu de Korn en una dirección optimista - optimismo heroico nacido de la confianza en que la voluntad, aplicada a la acción, ha de terminar al fin por imponerse y triunfar. Es como si lo nuevo hubiera vencido en Korn a lo viejo; América, la Argentina, a Europa; la acción al conocimiento (que no va más allá del conocimiento). Al fin es también en una filosofía argentina y para la Argentina en lo que el autor piensa. Dándose cuenta, se entiende, de que la Argentina, como el resto de América, pertenece al orbe de la cultura occidental, y reconociendo la necesidad de vivir en relación con esa cultura. Pero reconociendo igualmente, por otra parte, que la realidad de la vida argentina presenta caracteres particulares y problemas especiales, problemas que han de resol- 
verse, por consiguiente, según antecedentes también nacionales. Será, un día, el problema económico, de realidad tan ac-. tual en la vida de la nación, y del que el pensador nacional no podrá desentenderse; será, otro día, el problema de la capacidad económica ya lograda aplicada a fines de solidaridad humana y de cultura superior; y será, sobre todo, el problema de constituirse en nación con una personalidad propia y como tal conservarse. Ello supone una voluntad dirigida a un fin, a un ideal, ideal que, concluye Korn, habrá de ser en el caso de la Argentina, "la libertad lograda por la acción" $(\mathrm{I}, 149)$.

\section{IV}

Señala el profesor Francisco Romero, en su estudio introductorio a las Obras de Korn, entre los rasgos destacados de la personalidad del filósofo, el de una "austera voluntad de verdad" (I, II). Es, efectivamente, la impresión más fuerte que creemos deja la lectura de los escritos del autor. Eso, y cualidades que de eso resultan, y entre las que ha de mencionarse la de un noble sentido y sentimiento de humanidad. Humanidad a base de dignidad. No se trata sólo de una cuestión de razón, de inteligencia; una tal exigencia de verdad es siempre, en último término, una cuestión de personalidad, de carácter, de sentido ético.

Evidentemente, no se propuso Korn deslumbrar al público con los alardes de un pensar filosófico novedoso, ni, en realidad, se propuso filosofar para el público, lo que explica la relativa escasez de su producción escrita, más un cierto desprecio por las "filosofías de cátedra". Más que para el público filosofó para sí mismo, acuciado por el ansia de hacerse luz que a él le iluminase. No inventó por eso temas ni problemas nuevos; antes bien se enfrentó con los viejos y fundamentales problemas de la filosofía, que son también los de la vida espiritual, y entre el cúmulo de soluciones contradictorias, buscó la suya propia, que podrá o no coincidir con otras soluciones, pero que en todo caso es suya, porque como suya la repensó y vivió, marcándola así con la originalidad de su carác- 
ter independiente. Al fin, no es sólo un filósofo lo que en Korn descubrimos; es también un hombre - un hombre a quien una exigente necesidad espiritual lleva a hacer filosofía.

Posición ésta difícil, en la que lo filosófico corre el riesgo de mezclarse demasiado con lo humano. Pulcritud de Korn fué, sin embargo, haber sabido separar las dos cosas, $\mathrm{y}$, sin ir al extremo opuesto de una filosofía deshumanizada; antes bien, afirmando y poniendo lo humano en el primer plano (recuérdese la convergencia del pensar filosófico del autor en torno a la exaltación del principio de la personalidad y la libertad), haber al mismo tiempo respetado los derechos de la filosofía como tal, equivalentes a los derechos de la razón y de la verdad.

Así lo advertimos de modo especial en lo que se refiere al problema de la metafísica y lo metafísico. Sintió Korn vivamente las inquietudes de este problema, que empieza como problema de la cabeza y acaba como problema del corazón, o viceversa. Lo sintió, pero no logró resolverlo. No desde luego por el conocimiento, solución que vió como imposible, y no tampoco por la fe, que o no poseía, o si la poseía no la confesó, como extraña al conocimiento filosófico y científico. $Y$ esa fué indudablemente su prueba de honradez máxima: dejando abiertos los caminos personales de la emoción artística y de la emoción religiosa, haber reconocido y afirmado, juntamente con la necesidad de la metafísica, la imposibilidad de hacer de la metafísica ciencia, contradiciendo la que era apremiante exigencia de su naturaleza. No se engañó ni engañó; no dió como filosofía ni menos como ciencia lo que sabía no lo era; aceptó sencillamente la que estimó ser la verdad del caso. La verdad de razón, única que en el pensar filosófico debía contar.

Por esta honradez básica de su pensar; por este su espíritu de veracidad, como pensador y como hombre, respetamos y admiramos a Korn. En el caos de la superchería y la disolución intelectual en que vivimos, es el espíritu de hombres así lo único merecedor de respeto.

CÉsar Barja, Universidad de California, Los Angeles. 
(1).-Ciencia y filosofia, Madrid, sin fecha, p. 110.

(2).-Discute las varias direcciones de este movimiento (la fenomenológica de Max Scheler; la idealista de Rickert; la idealista-realista de Münsterberg; y la realista de William Stern) August Messer, Deutscbe Wertpbilosophie der Gegenwart, Leipzig, 1926. En España publicó un excelente ensayo J. Ortega y Gasset: "¿Qué son los valores?", en Revisia de Occidente, octubre, 1923, pp. 39 y ss. Las ideas de Ortega acerca de la naturaleza de los valores, tal como las expone en este ensayo, difieren radicalmente de las sustentadas por Korn.

(3).-J. S. Haldane, The Sciences and Pbilosopby, New York, 1929.

(4).-Del sentido y direcciones de esta reacción, que no sólo alcan$\mathrm{za}$ al posicivismo sino también, en varias cosas, al idealismo $\mathrm{y}$, en general, al espíritu y pensamiento todos del siglo XIX, da una excelente idea el estudio de Karl Joël, "Die Überwindung des 19. Jahrhunderts im Denken der Gegenwart", en Kant-Studien, Vol. 32, 1927, pp. 475 y ss.

(5).-En ctro lugar (Libros y autores contemporáneos, Madrid, 1935), al discutir la doctrina de Ortega y Gasset de una "cultura vital", hemos debido ocuparnos de este complejo problema. De querer añadir hoy algo sería para insistir más y más en el resultado disolvente de la función intelectual que no se apoya más que en sí misma. 